\title{
WIMAX Implementation of Smart Grid Wide Area Power System Load Protection Model in MATLAB/SIMULINK
}

\author{
Asadullah Khan ${ }^{1}$, Muhammad Ali ${ }^{1}$, Ishtiaq Ahmad ${ }^{1}$, Amjad Ullah', Haseeb Ur Rahman², \\ Hafeez Ur Rahman ${ }^{3}$ \\ ${ }^{1}$ Electrical Engineering Department, COMSATS Institute of Information Technology, Abbottabad, Pakistan; ${ }^{2}$ Electrical Engineering \\ Department, NWFP University of Engineering \& Technology, Peshawar, Pakistan; ${ }^{3}$ Electrical Engineering Department, Ghanhara \\ University, Peshawar, Pakistan. \\ Email: mohammad-a@live.com
}

Received June 27 ${ }^{\text {th }}$, 2012; revised August $1^{\text {st }}$, 2012; accepted August $8^{\text {th }}, 2012$

\begin{abstract}
As the revolutionary change in electric power industry begins with the latest communication infrastructure, it is on the verge of a revolutionary transformation to develop a smart grid to meet the requirements of our digital society. Wide Area Power System is made up of plentiful automated transmission and distribution systems with strong communication infrastructure, all operating in a coordinated, proficient and reliable mode. This paper is fretful with the wide area power system load protection scheme and ensuing design requirement that enhances stability as well as control. It discusses the architecture that upgrades the existing scheme by controlling all the control signals traffic between generating units, server, connected loads, and protection devices using WIMAX. The main theme of the paper is on the use of information technology to obtain more flexibility and smartness in the Wide Area Power System Load Protection by designing the Communication channel using WIMAX. Faults detected in Local area networks and Information regarding the faults of Local Areas is communicated to Load Area Manager (LAM) which takes required control action to handle it. Finally the paper shows islanding operation through WAM for the areas that becomes intensive faulty. Results have been verified in MATLAB/ SIMULIMK.
\end{abstract}

Keywords: WIMAX; Wide Area Network (WAN); Wide Area Manager (WAM); Local Area Manager (LAM)

\section{Introduction}

Wide Area Smart Grid Architecture defines a set of plausible scenarios spanning the entire energy enterprise utility, industrial, commercial, farm, agriculture and residential. The scenarios then enable analysis on the data and resulting communication requirement needed to construct a complete high level set of functions for the communication infrastructure. In the United States the bulk electric power system is operating ever closer to its reliability limits. The past decade has seen many efforts to achieve a smart grid that is, using digital technology to save energy, reduce cost, increase reliability, and transparency. Special efforts have been made to seek preventive and restorative methods for dealing with likely wide spread catastrophic failures, which are caused either by unanticipated disturbances, such as the North American blackout on 14th August 2003, or International attacks. It has been widely agreed [1] that there are inseparable interdependencies between reliable, robust, efficient operations of power grids, the efficient placement, and operation of related telecommunication networks, as pointed out in the work of Heydt et al. The importance of smart grid operations allows for great penetration of variable energy sources through the more flexible management of the system. This can be achieved in many ways from active demand and load side strong communication using temporary storage technologies [2,3].

Today's network infrastructure, largely based on synchronous optical network and synchronous digital hierarchy technologies, cannot physically or economically support the ever changing demands caused by the overwhelming increase in bandwidth, transport of IP traffic, and the need for more flexible connectivity, higher resiliency, and network automation. To address this concern and main competitive, service providers have been investing heavily in building next-generation networks. Indeed, it is important to review how existing communication technologies such as IEEE 802.11 Wi-Fi, IEEE 802.15.4 ZigBee, Bluetooth, and so on respond to the bandwidth and delay requirements of Smart Grid.

In the smart grid smart meters, home gateways, and consumer devices server and respective clients commu- 
nicate via wireless communication [4]. Moreover consumer can become small-scale suppliers by generating green energy at home, consume this power locally and sell the excess power to the utilities. The emerging IEEE 802.16 Broadband Wireless Access technology WIMAX [5] allows interoperability and combines the benefits that other wireless networking technologies offer individually and leads a path towards $4 \mathrm{G}$. The WIMAX spectrum uses for voice, video, and data all considered broad band Wireless Access applications. WIMAX technology enables ubiquitous delivery of wireless broadband [6] service for fixed and/or mobile users, and became a reality in 2006 when Korea Telecom started the deployment of a 2.3 GHz version of mobile WIMAX service called WI$\mathrm{BRO}$ in the Seoul metropolitan area to offer high performance for data and video up to $50 \mathrm{~km}$.

Utility needs and problems are often formulated in very loose terms, such as "intelligent load shedding," "protection system against major disturbances," and “counteract cascaded line tripping." These needs have to be broken down to physical phenomena [7], such as protection against: transient angle instability (first swing), small signal angle instability (damping), frequency instability, short-term voltage instability, long-term voltage instability, cascading outages.

The most fundamental requirement in any electrical system is proper over current protection to prevent the load from overheating and electrodynamics interactions. This article provide a detail client server bidirectional load protection system model for wide area Smart Grid network and focus on over current Power System Load Protection implementation in MATLAB/SIMULINK using WIMAX. The paper also highlights WIMAX transmitter and receiver model for desired wide area monitoring and control.

\section{Related Work and Problem Formulation}

The purpose of Power System Load Protection Model is to keep the power system stable by isolating only the components that are under fault, whilst leaving as much of the network as possible still in operation. Joachim Bertsch, Cedric Carnal, Daniel Karlsson, John Mcdaniel, and Khoi $\mathrm{Vu}$ [7] integrate the local protection center into wide solution with System Protection Scheme. These local protection centers form system Protection Scheme, while the interconnected coordinated system forms a defense plan [8,9]. Protection systems against voltage instability can use simple binary signals such as "low voltage" or more advanced indicators such as power transfer margins based on the VIP algorithm [10] or modal analysis.

Transients in substations [11] may result in current surges through the substation grounding system. Ground
Potential Rise can affect the communication system located near the protective relays or communication facilities outside the substation perimeter. The Electromagnetic Interface and Ground Potential Rise problem, IEEE recently developed a new standard [12] to define an optical digital interface between relay and multiplexer. IEEE [13], ANSI and IEC Standards define transient and Surge Withstand Capabilities that should be met. Protection Model must apply a very pessimistic and pragmatic approach to clear system faults to a normal state and diminish the impact of the disturbances, the protection and control actions are required to stop power system degradation and system wide disturbances are growing issue for the power system industry [14,15].

Powerful, reliable, sensitive, and robust, Wide Area Power System systems are [16] installed in substations, where actions are to be made or measurements are to be taken. Actions are preferably local, i.e., transfer trips should be avoided in order to increase security. Relevant power system variable data is transferred through WIMAX that ties the terminals together. Different schemes should be needed to be broken down to physical phenomena, such as protection against voltage instability, frequency instability, transient angle instability, and cascaded outages.

Development of microprocessor protection [17] device based on IEC61850 on the high speed DSP hardware platform is an unavoidable trend for substation automation. A PLC-based load shedding scheme offers many advantages, such as the use of a distributed network using the power management system, as well as an automated means of load relief. However, in such applications monitoring of the power system is limited to a portion of the network with the acquisition of scattered data. This drawback [18] is further compounded by the implementation of pre-defined load priority tables at the PLC level that are executed sequentially to curtail blocks of load regardless of the dynamic changes in the system loading, generation, or operating configureuration. The system wide operating condition is often missing from the decision-making process resulting in insufficient or excessive load shedding. In addition, response time (time between the detection of the need for load shedding and action by the circuit breakers) during transient disturbances is often too long requiring even more load to be dropped.

Real-time communication IEC 61850 [19] mechanisms through Generic Substation State Event, Generic Object Oriented Substation Event per 61850-7-2, IEC 61850-9-1 Sampled analog values over serial unidirectional point-to-point link, and IEC 61850-9-2 Sampled analog values over VLAN/priority-tagged Ethernet network are very powerful but they still lack support for some of the most demanding substation applications, 
such as precision time synchronization (5S pts), line differential, and bus differential protection.

Strong client server communication WIMAX architecture is provided in MATLAB which enhances reliability provides intelligent control updates wide area manager (WAM) server for each and every instant which uproots the over current and under voltage faults when exceeding required thresholds. WAM provides bidirectional wireless communication channel to local area manager (LAM) for intelligent operations. Each LAM acting as a server communicates with respective area clients through WIMAX. The Model consists of compulsory loads spreading in the wide area (i.e. Residential, Commercial, Farm, Agricultural and Industrial), each type of loads as mentioned above are further expended in to its local clients. These local clients are consisting of various types of loads specially the industry and the farm loads consisting of 3-phase motors. Through bidirectional communication, internal faults are tackled by LAM and external faults are handled by WAM.

\section{Wide Area Control Design}

The Wide Area smart grid Architecture for power system load protection is shown in Figure 1. The architecture consists of various area loads i.e. Residential, Commercial, Farm, Agriculture, and Industrial. The residential and commercial load consists of resistive and inductive loads, the farm load, Agriculture load and Industrial load consisting of resistive, inductive and three-phase motor loads. The loads are controlled by wide area manager and further clients of each load are controlled by a local area manager (LAM). Control area Manager of each client receives signals from fault sensing system which send control signals to WAM through WIMAX sender/receiver and control each area through bidirectional communication as shown in Figure 2.

Figure 2 consists of flow chart of the whole wide area smart grid architecture in which the generating sources composed of renewable energy resources including wind power plant and solar panels. The wide area manager is the centralized portion which is the main soul of the complete wide area smart grid architecture which got its intelligent control due to its computational engine and data user defined cases. Due to these circumstances the WAM accurately control its area using WIMAX through bidirectional communication.

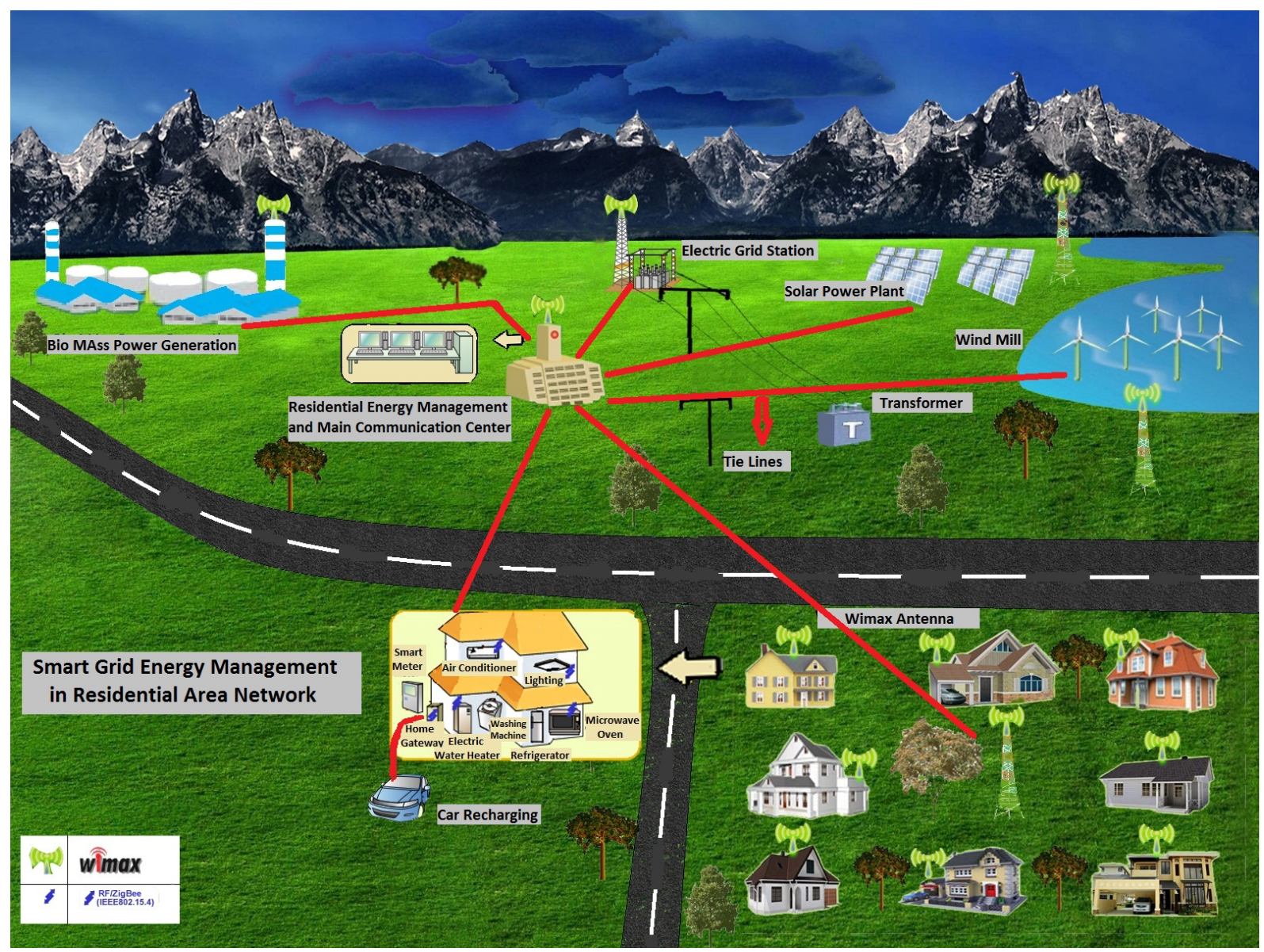

Figure 1. Wide area smart grid architecture. 


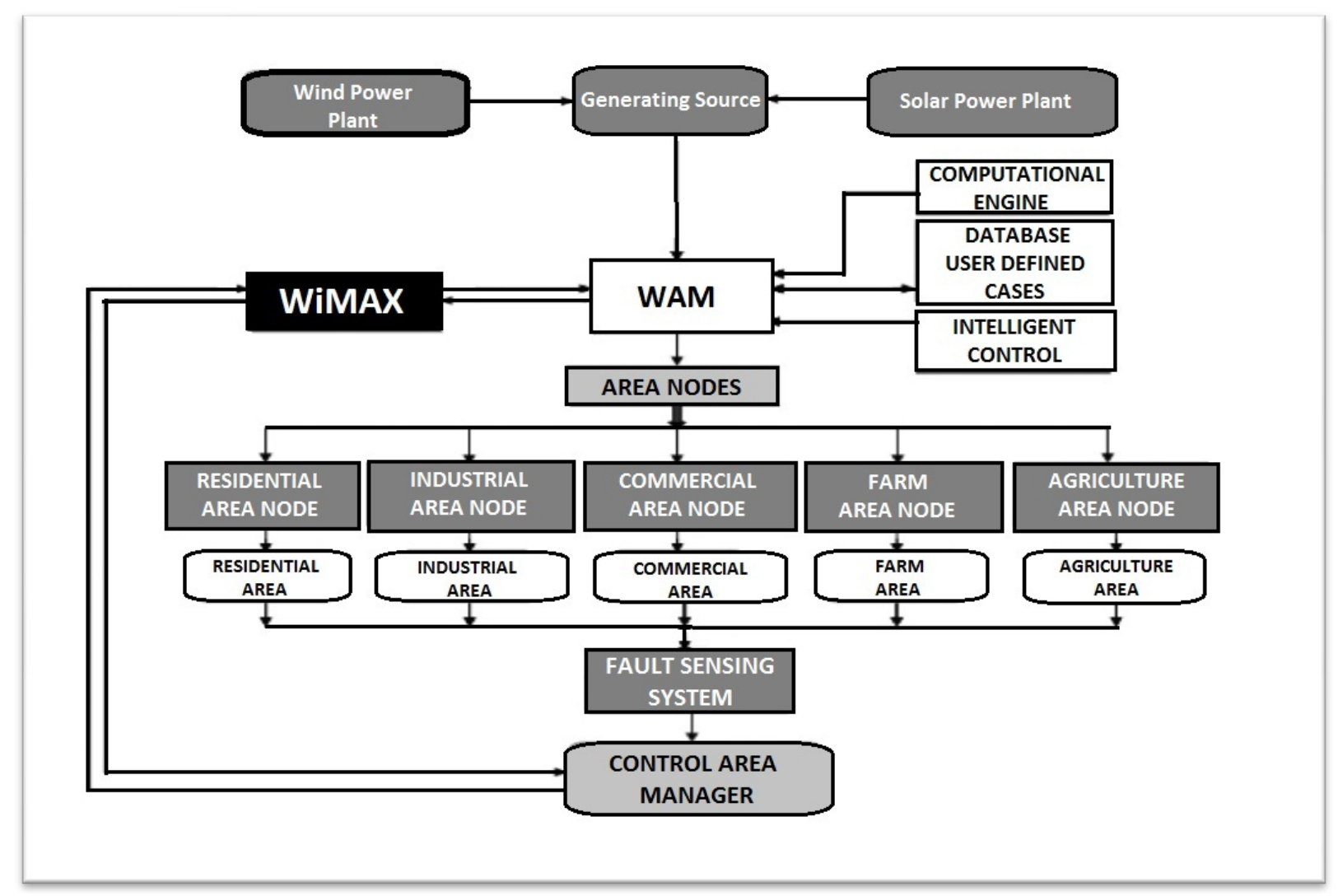

Figure 2. Wide area block diagram.

The internal flow chart of industrial portion is shown in Figure 3; fault sensing system senses the abnormal conditions and sends signal to local controller from where the signal is processed by transmitter to the LAM through WIMAX. Local controller and LAM shows bidirectional communication architecture in local clients. Each load as shown in the flow chart of industrial area had its own load controller, fault sensing relay system and circuit breaker. That is for the purpose of uprooting only the faulty load portions.

The complete scenario of the above mentioned smart grid architecture along with it flow charts is shown in Figure 4, which briefly explains the wide area power system load protection, consisting of three area loads and are controlling by wide area manager (WAM) in MATLAB/SIMULINK. The system given below have primary protection on the main line along with transmitter and receiver, If the secondary protection on the distribution line fails or if the fault occurs on the main primary line of the generating station then it's the primary protection to trip all the loads. While intelligent protection is one which isolates only the faulty portion, which is also implemented in all loads. The below system also show five areas which are industrial, commercial, farm, agricultural and residential along with their sub-systems which are explained in Figure 4.
Figure 5, show the wide area manager (WAM) receiving data through receiver and sending data through transmitter the fault sensing system send data through WIMAX received by receiver of the WAM and send the control signal via transmitter to the circuit breakers of each area.

The internal sub-system of industrial loads is shown in Figure 6, which has three sub areas (i.e. Resistive, motor and R-L loads) the internal sub-system. The internal Local area manager shown in Figure 6 controls the internal clients of each sub-load.

Figure 3 shows the internal sub-system of Industrial Motor load. The motor load consists of five motors each consisting of intelligent and smart WIMAX transmitter and receiver along with relay and circuit breaker. When the over current fault (i.e. Phase A to ground) occurs in the three-phase motor the relay sense the fault and convey the data via transmitter to receiver, there after the receiver convey the trip signal to circuit breaker. The circuit breaker operates and isolates the faulty client without the interruption of other clients load. Hence intelligent protection system is justified here because only a faulty load in the zone is isolated without the disturbance of the rest of the Areas load.

The overall drift in the voltage and current wave form indicates type of fault (e.g. Phase A to ground). It also 


\section{FLOW CONTROL OF AN INDUSTRIAL} AREA

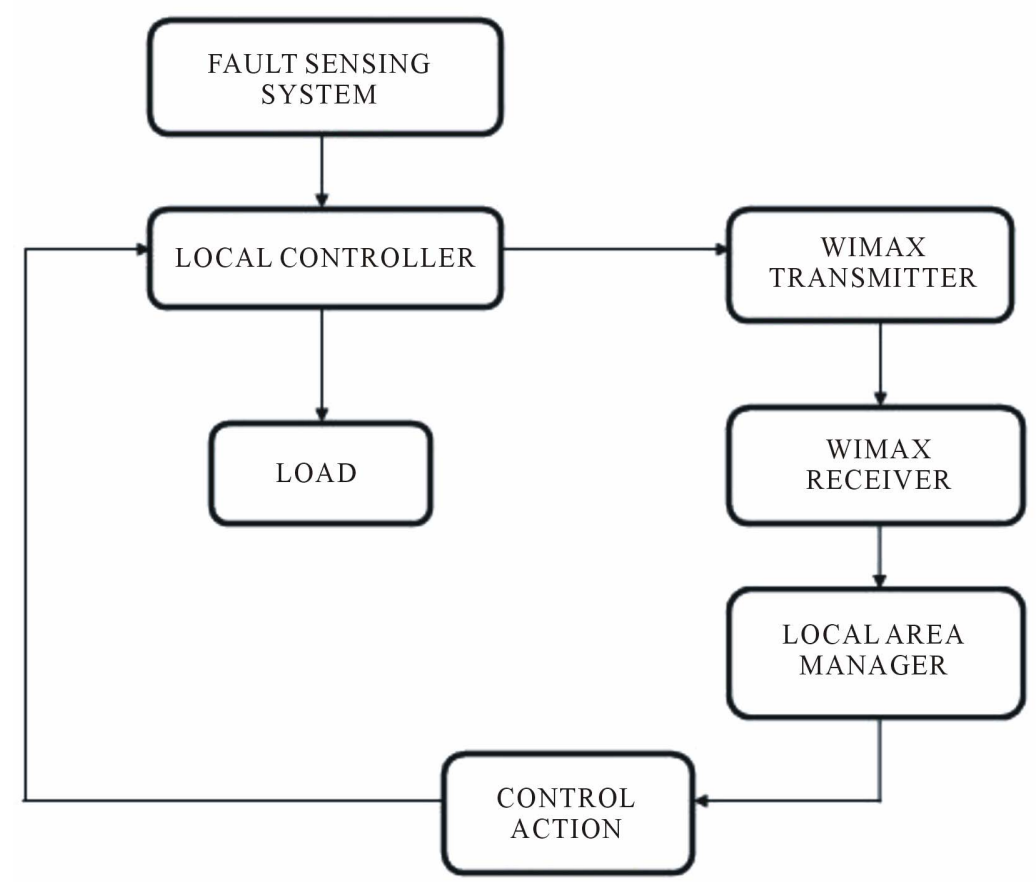

Figure 3. Industrial load block diagram.

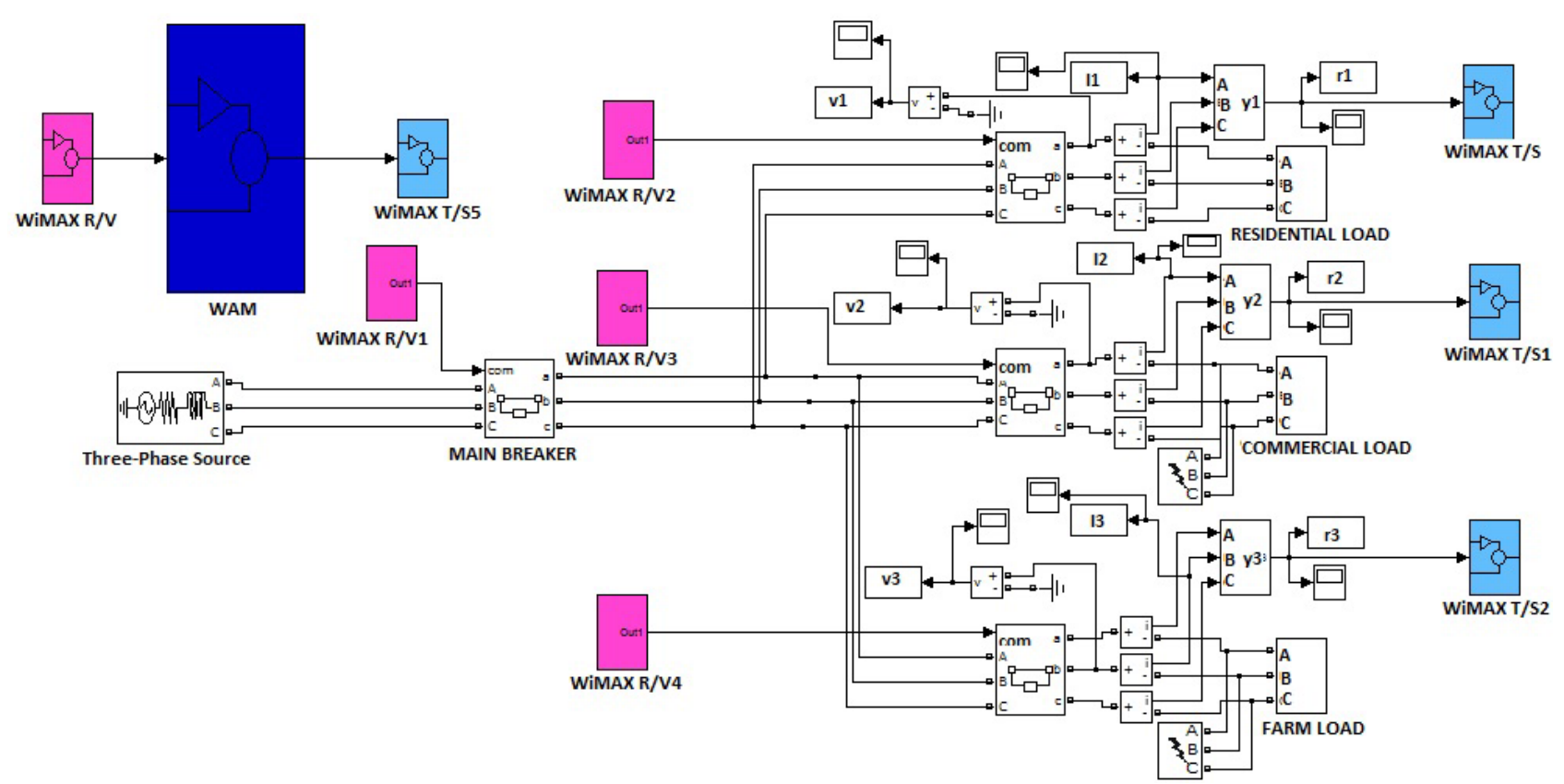

Figure 4. Wide area power system load protection SIMULINK diagram.

points to other characteristics of the fault and the behavior of the protection system. Events and protection system operation analysis includes the following checks.

- Relay and breaker contacts state is tested for a change and indicates that the protection system has detected a fault.

- When phase to ground fault occurs or over current fault occurs due to any other natural phenomena, the relay will sense the fault and send trip signal to WIMAX transmitter. 


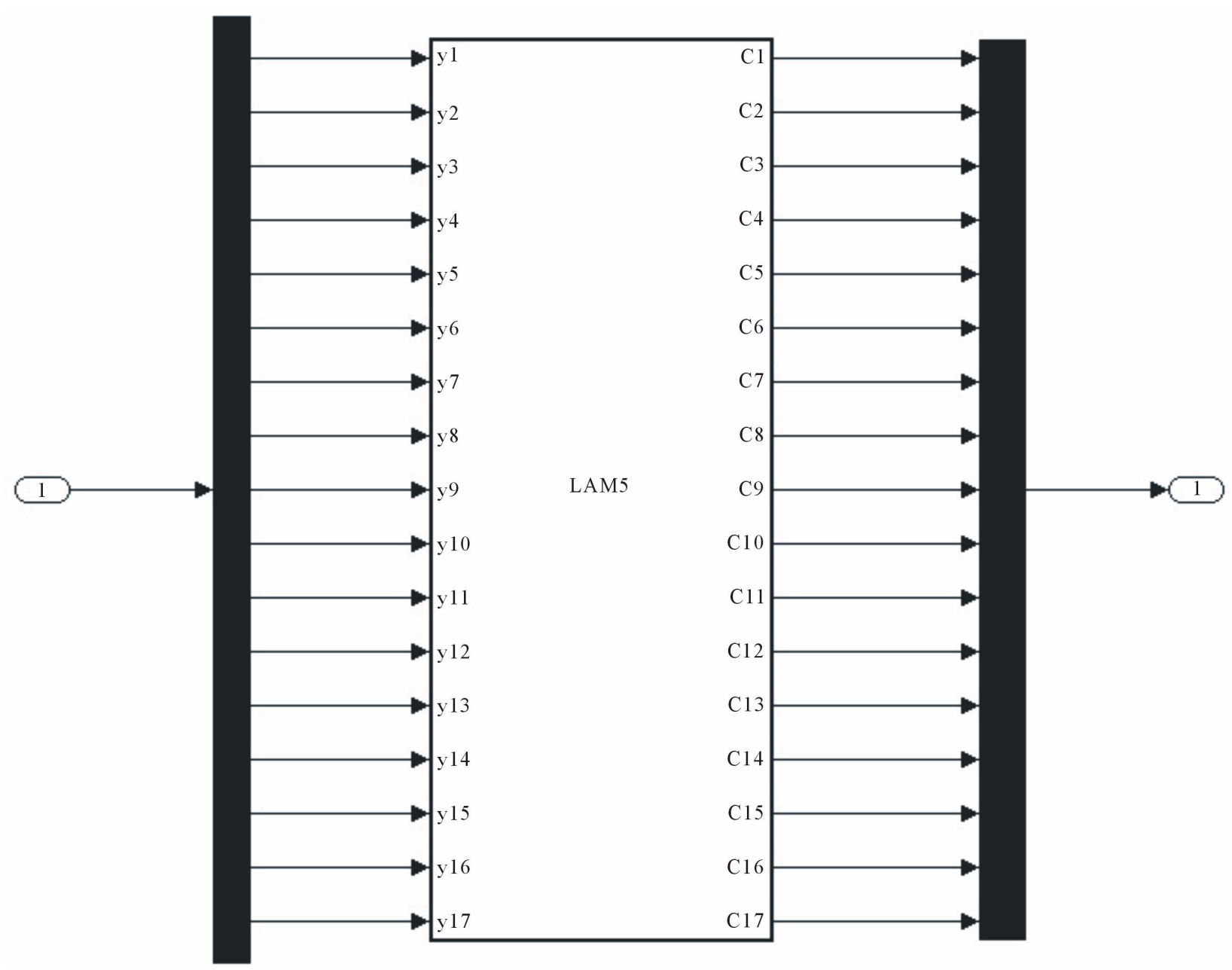

Figure 5. Wide area manager SIMULINK block.

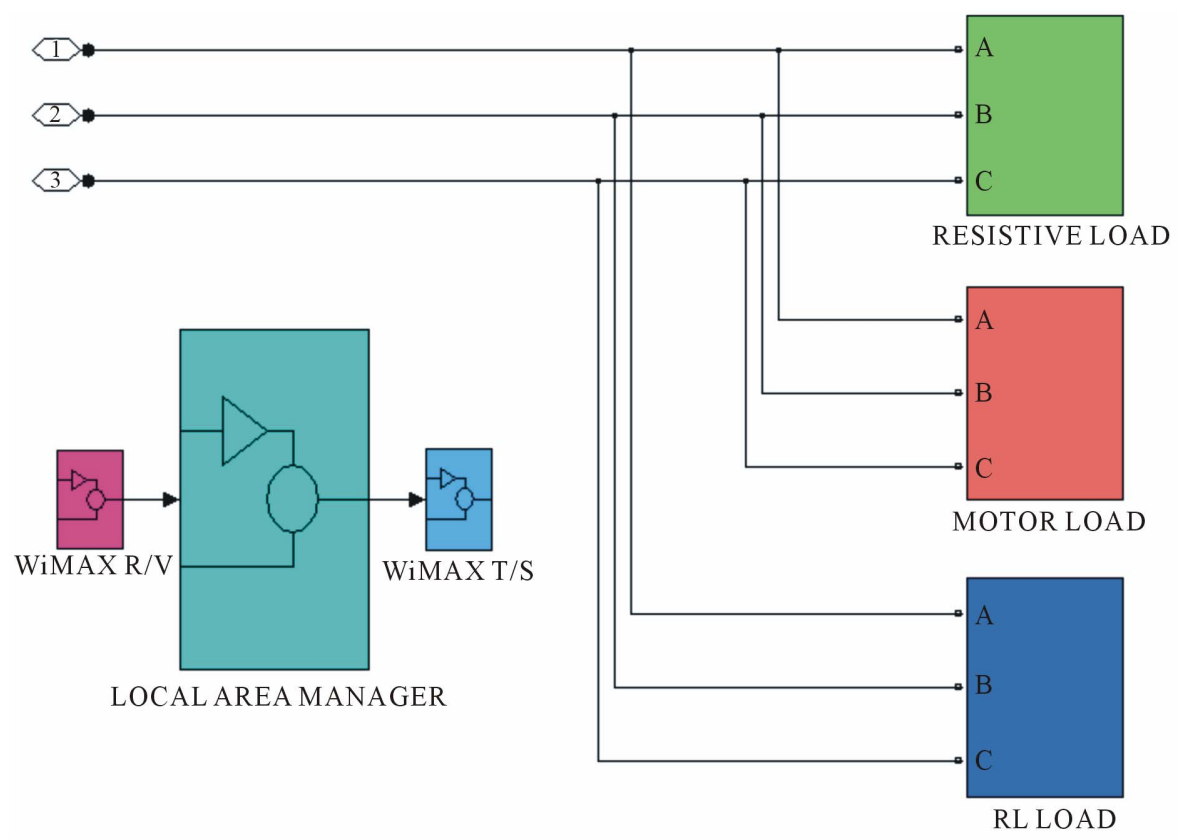

Figure 6. Industrial load. 
- The WIMAX receiver will receive the trip signal and transfer the signal to the server.

- It's the server to decide the fault occurring side and trip the faulty load through circuit breaker without any interruption in the rest of the system.

\section{Result and Simulation}

Figure 7 shows the Residential Area Load, single phase current graph. The Residential Area Load is normal load means no kind of any disturbance or fault occurred at this load. Figure shows that before the maximum peak, the value of current is normal, as the fault occur the current shoots up to higher value. The reason behind the condition is by tripping the faulty load, which is connected parallel to the residential load.

Similarly in Figure 8 the voltage of the residential load also increased from its normal value because of the tripping of the faulty section.

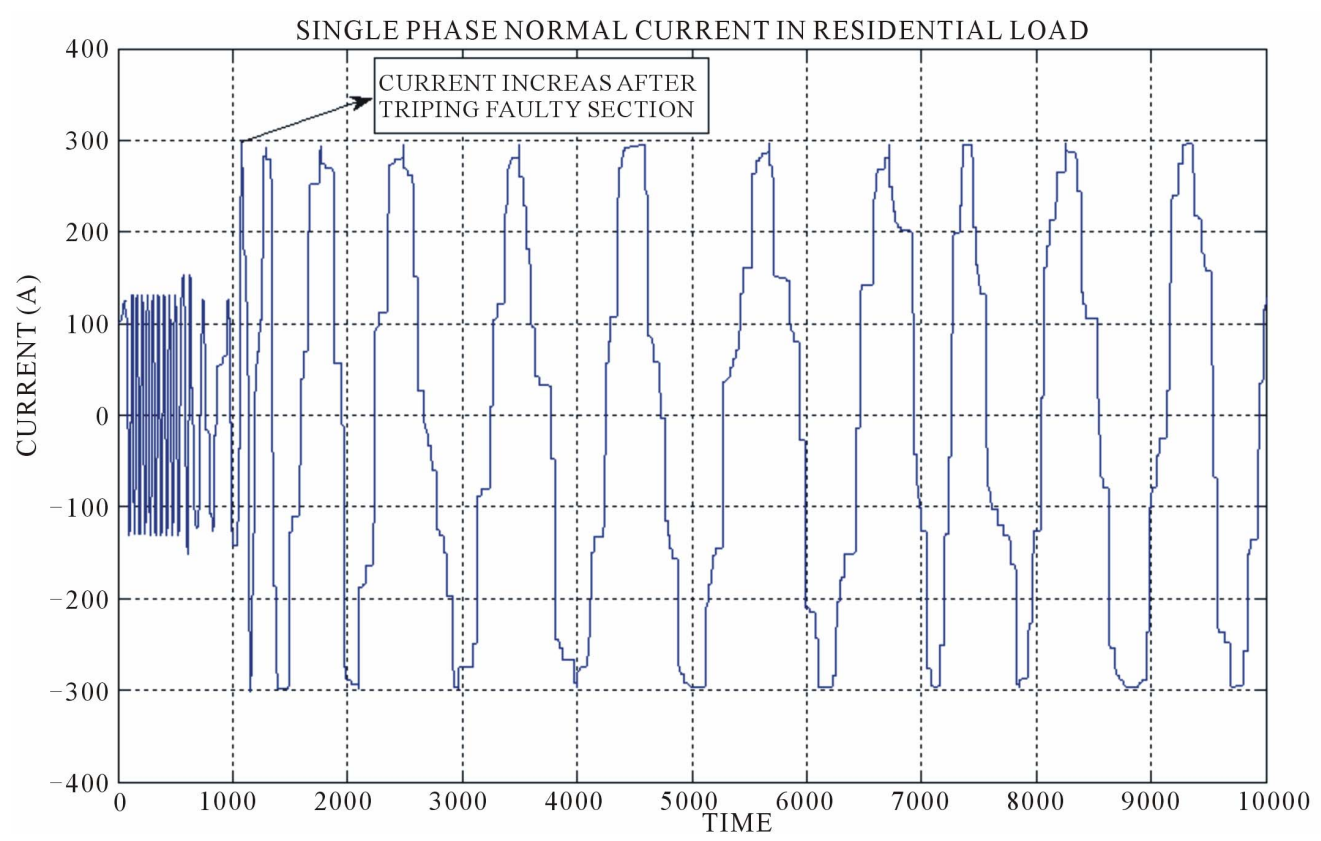

Figure 7. Residential area load current.

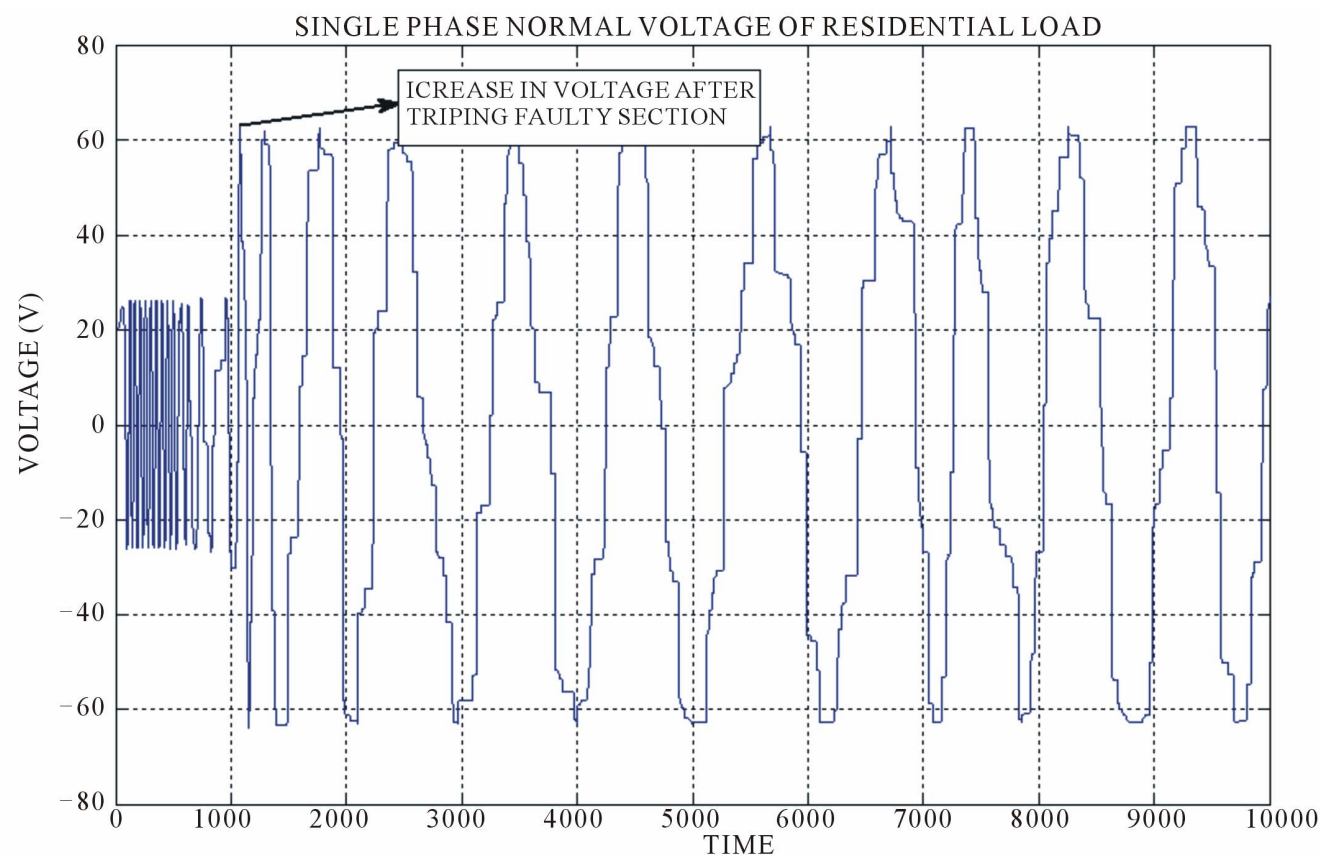

Figure 8. Residential area load voltage. 
Figure 9, mention the three-phase Industrial Area Load current plot. The highest peak shows the phase B to ground fault, after that the load has been tripped by tripping system. Similarly in Figure $\mathbf{1 0}$ after the tripping of the Industrial load, the voltage curve also becomes equal to zero. Figure 11 shows single phase fault current of Industrial Load, after the occurrence of fault it has been cleared by the tripping system. Figure 12 shows voltage dip occurred in the faulty section at the time of fault, and then goes to zero after the tripping of circuit. Figure 13 shows the single phase fault current of Commercial Load, the fault current is being cleared after occurrence of fault. Figure 14 shows the single phase voltage curve of the Commercial Area Load. Figure 15 shows fault behavior of single phase industrial load and Figure 16 shows fault behavior of three-phase farm load.

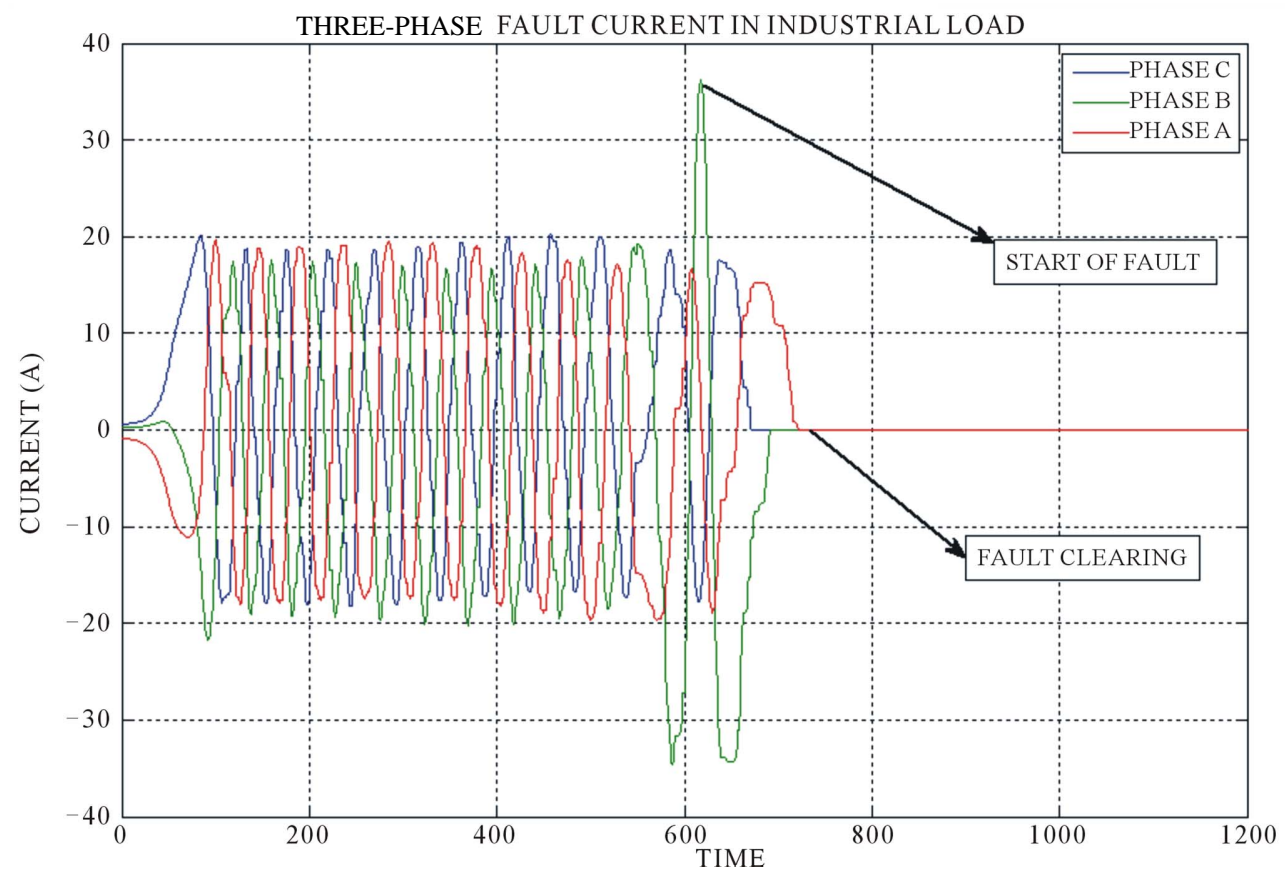

Figure 9. Three phase fault current of industrial load.

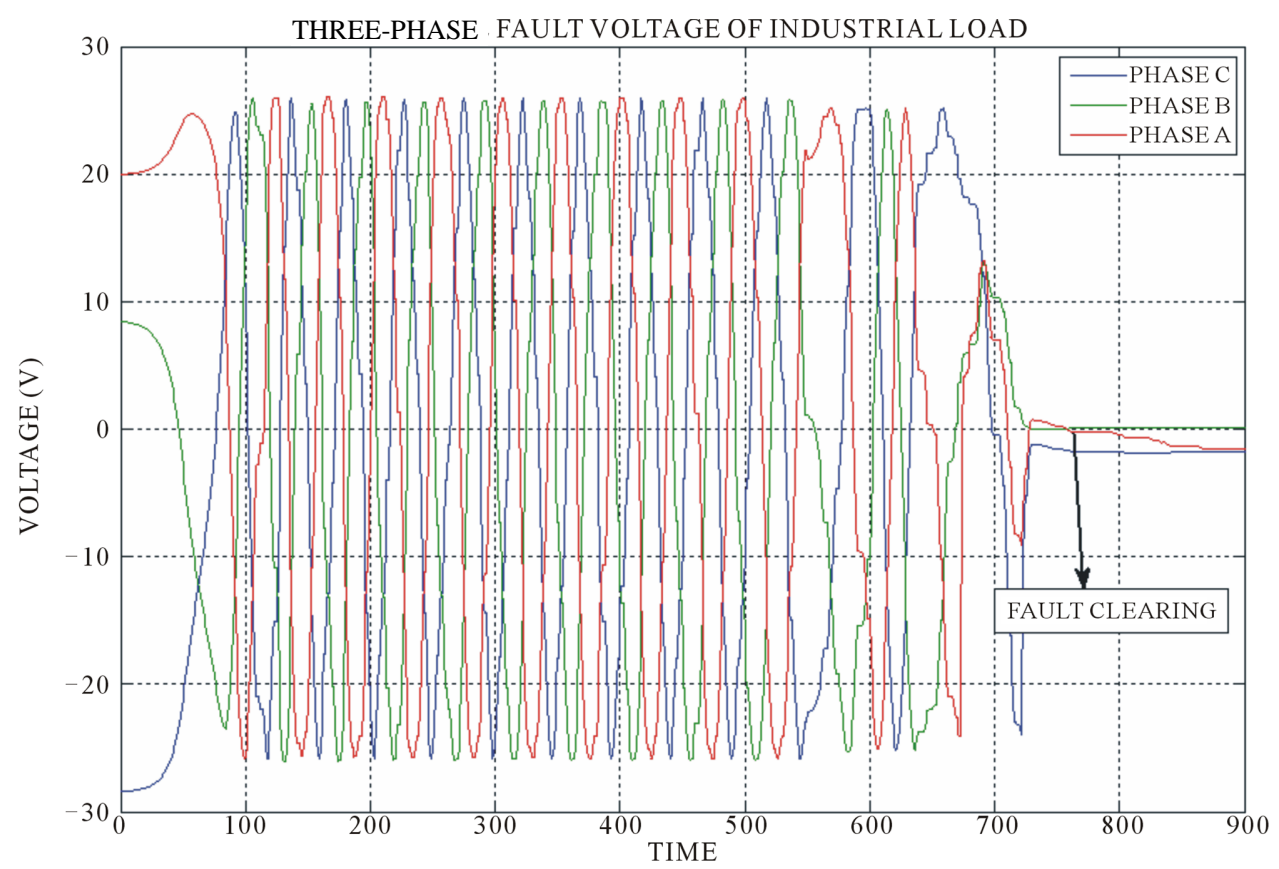

Figure 10. Three phase fault voltage of industrial load. 


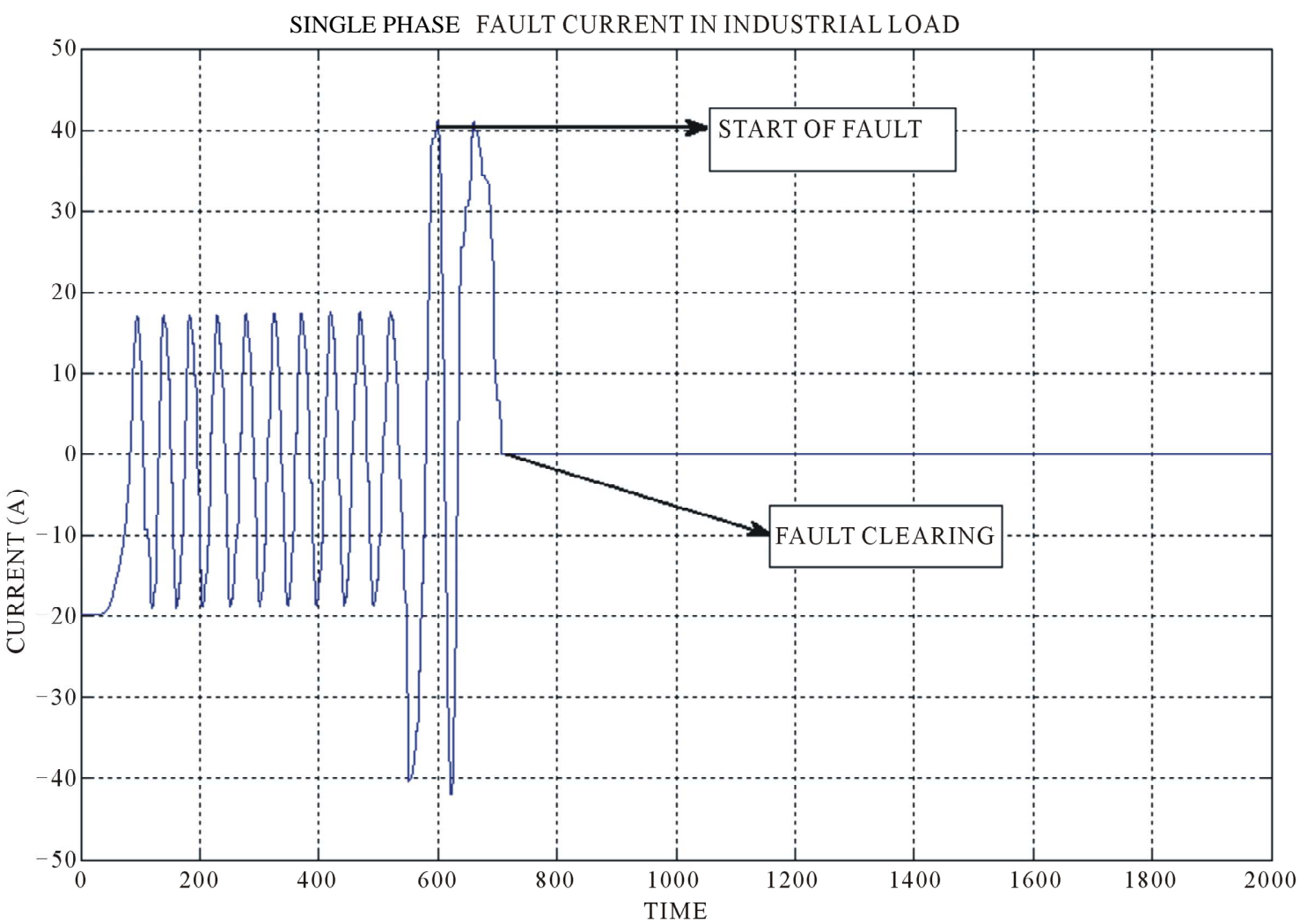

Figure 11. Single phase industrial load fault current.

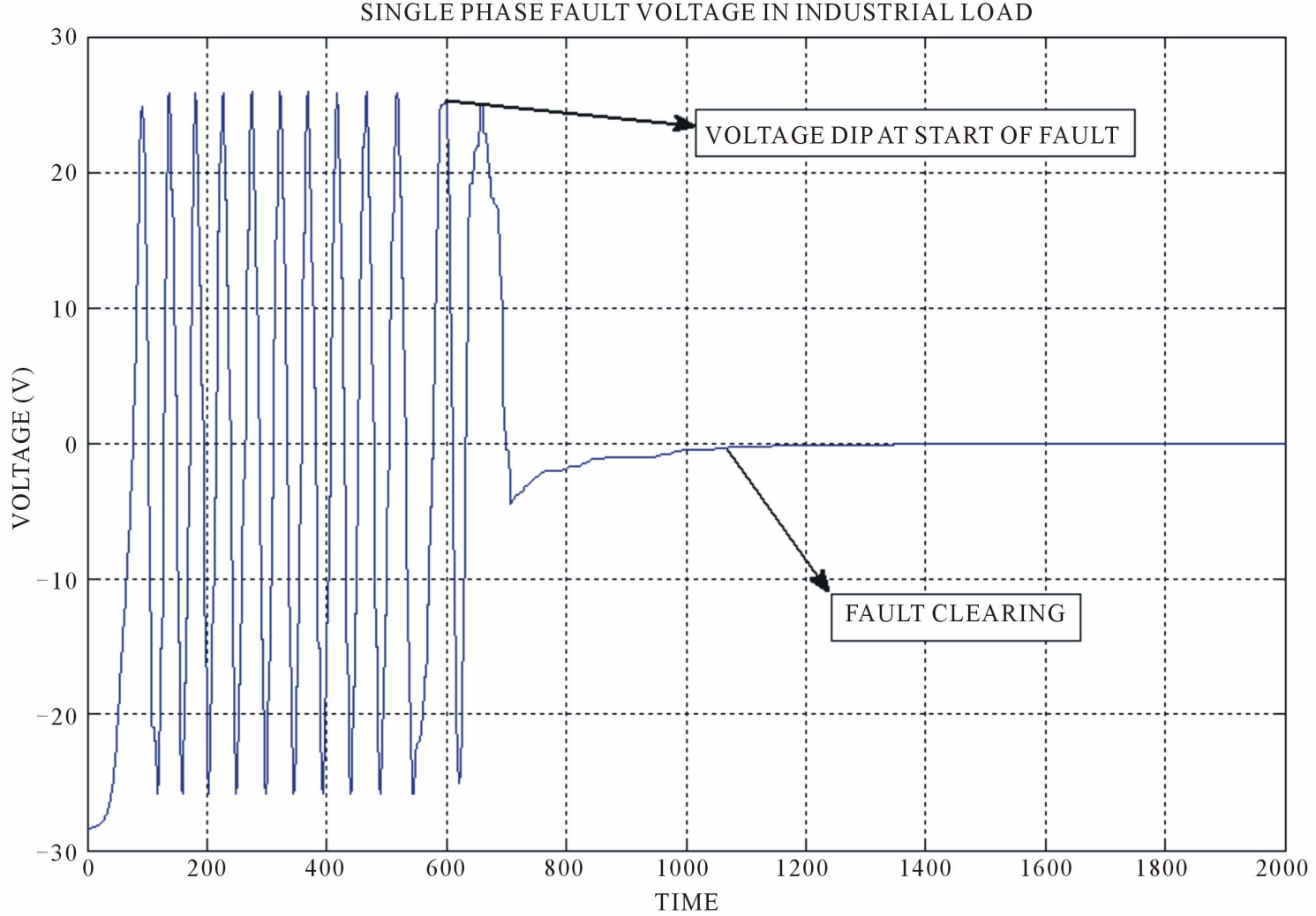

Figure 12. Single phase industrial load fault voltage. 


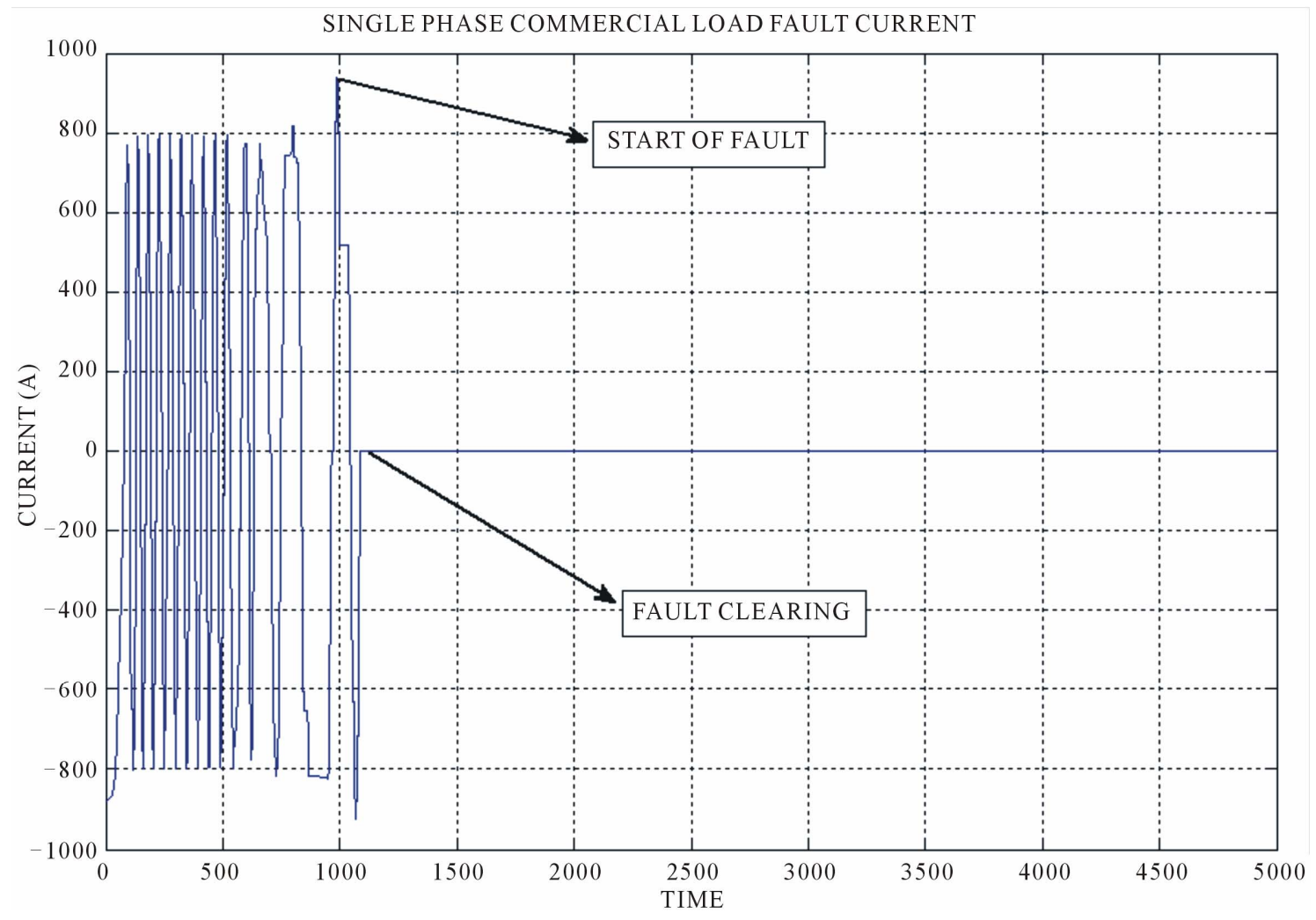

Figure 13. Commercial load fault current.

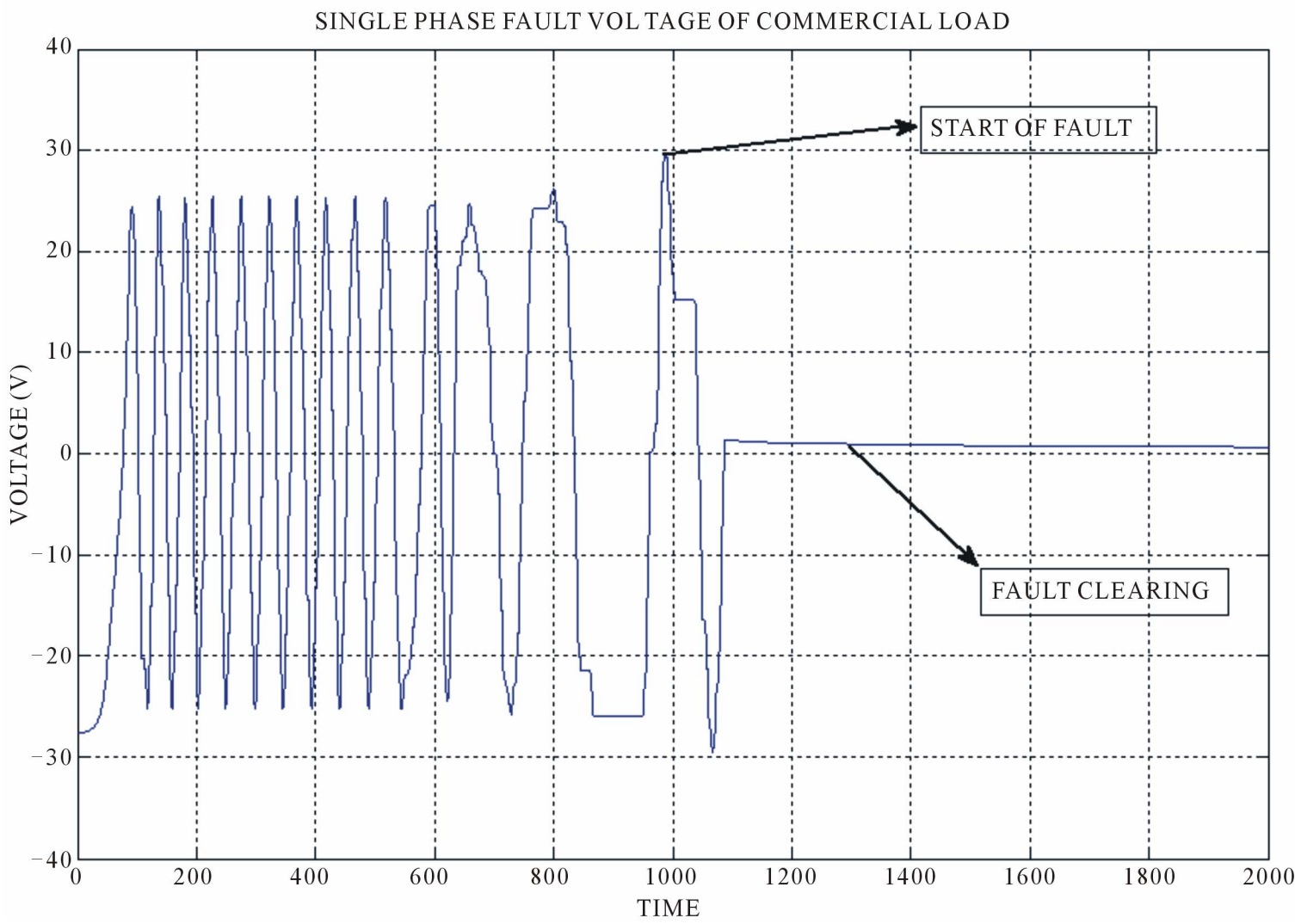

Figure 14. Commercial load fault voltage. 


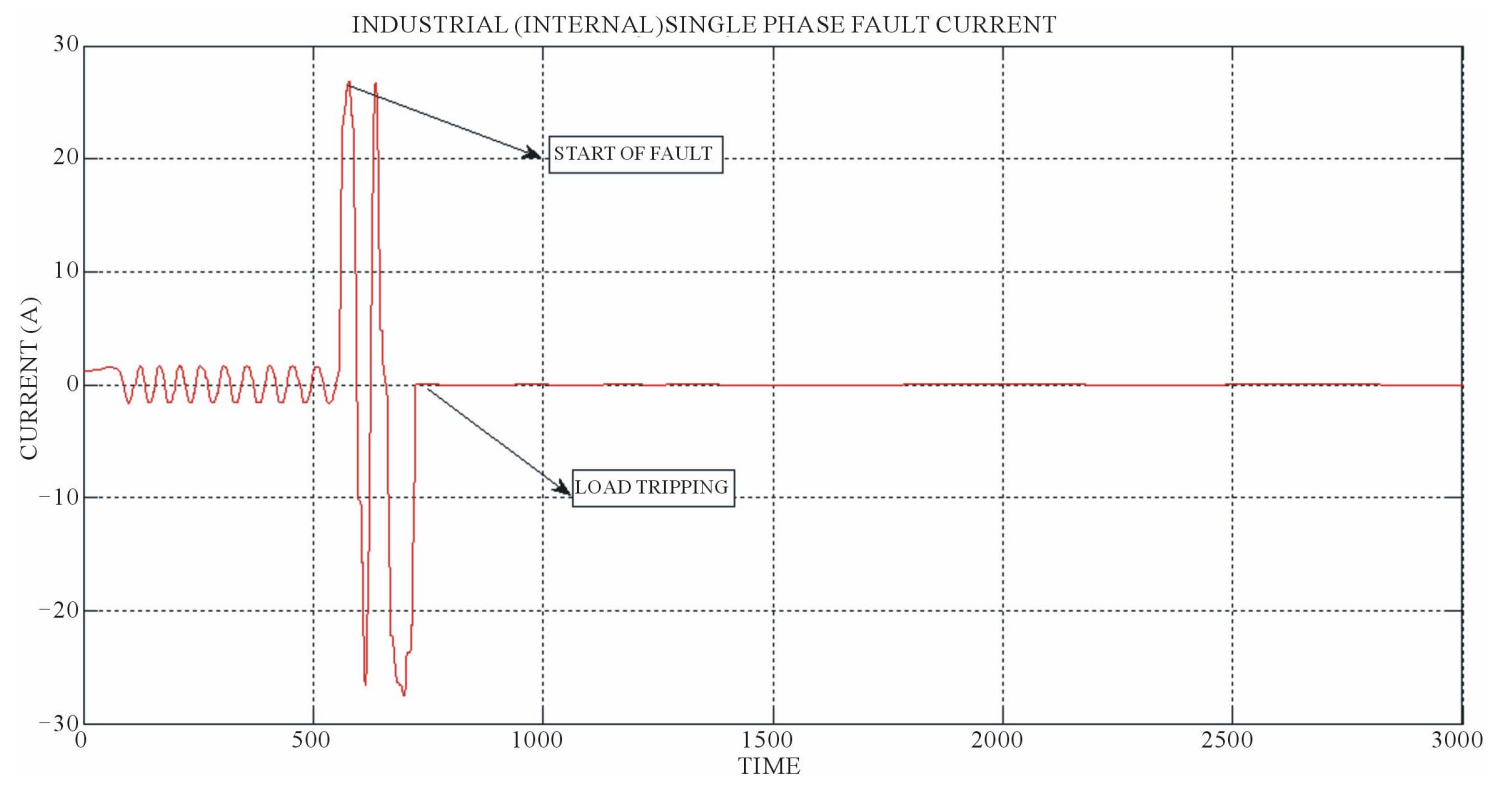

Figure 15. Single phase industrial motor load fault current.

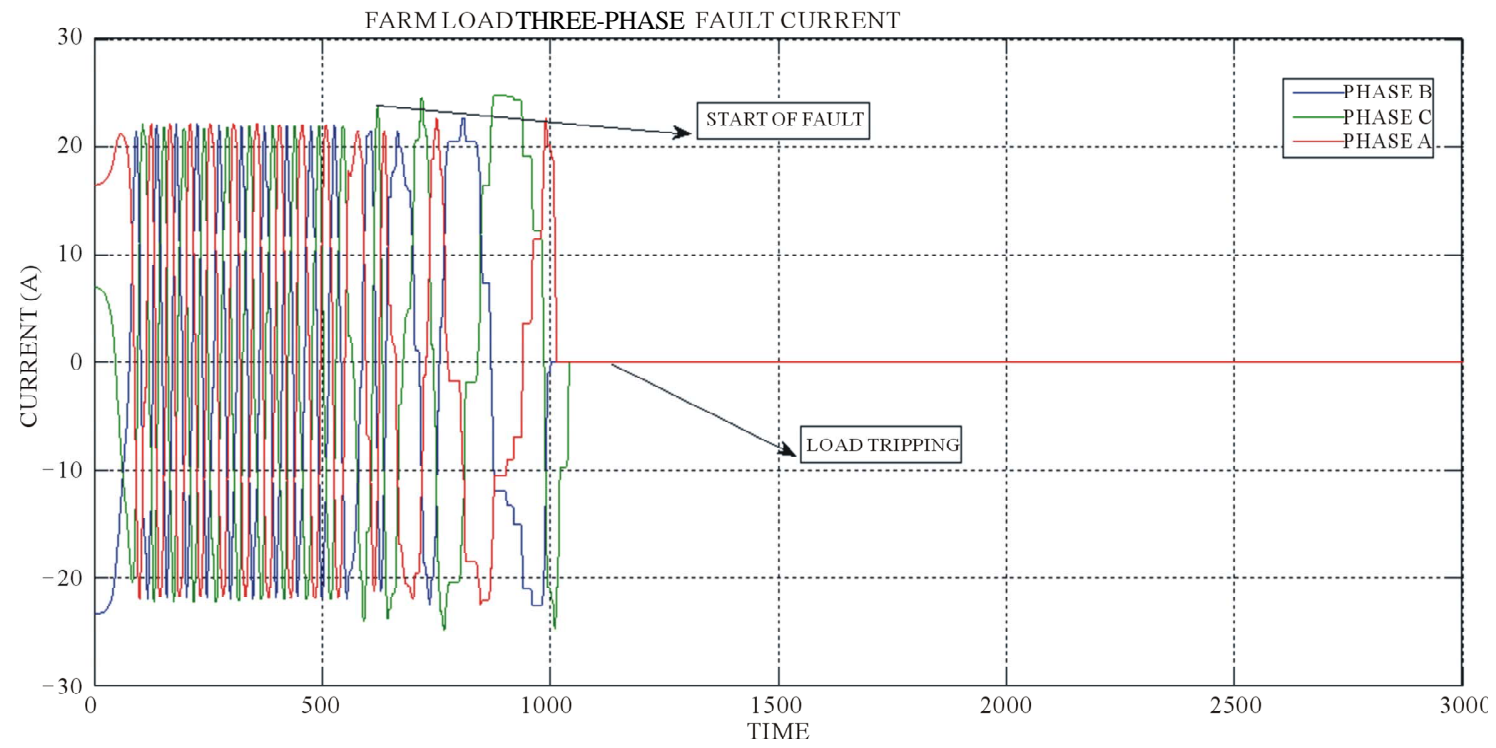

Figure 16. Three phase farm external area load fault current.

\section{Conclusion}

This paper has discussed terminology, phenomena, and solution implementation strategies for wide area power system load protection. We propose the following flow charts and design system expressing the Wide Area Power System Load Protection through WIMAX. The use of WIMAX has greatly improved the observe ability of the power system dynamics. Based on WIMAX different Wide Area Power System load protection is designed in MATLAB/SIMULINK. This paper illustrates the benefits of Wide Area Power System load protection using WIMAX reduced the risk of system collapse. This scheme would allow the smart grid systems operator more flexibility to operate the power system and utilize the generation resources more efficiently.

\section{REFERENCES}

[1] G. Heydt, C. Liu, A. G. Phadke and V. Vital, "Solution for the Crisis in Electric Power Supply," IEEE Computer Applications Power, Vol. 14, No. 3, 2001, pp. 22-30. doi:10.1109/MCAP.2001.952933

[2] M. Begovic, V. Madani and D. Novosel, "System Integrity Protection Systems," IREP Symposium of Bulk Power System Dynamics and Control VII, Charleston, August 2007.

[3] I. Dobson, J. Chen, J. Thorp, B. Carreras and D. Newman, 
"Examining Critically of Blackouts in Power System Models with Cascading Outages,” 35th International Conference on System Sciences, Big Island, January 2002.

[4] M. Erol-Kantarci and H. T. Mouftah, "TOU-Aware Energy Management and Wireless Sensor Networks for Reducing Peak Load is Smart Grids," IEEE 72nd of Vehicular Technology Conference Fall, Ottawa, 6-9 September 2012, pp. 1-5.

[5] K. R. Santhi and G. S. Kumaran, "Migration to 4G: Mobile IP Based Solutions," Proceedings of the Advanced International Conference on Telecommunications and International Conference on Internet and Web Applications and Services, 19-25 February 2006, p. 76.

[6] W. Roh and V. Yanover, "Introduction to WiMAX Technology," WiMAX Evolution: Emerging Technologies and Applications, John Wiley \& Sons Ltd., Chichester, 2009.

[7] J. Bertsch, C. Carnal, D. Karlsson, J. Mdaniel and K. Vu, "Wide-Area Protection and Power System Utilization," Proceedings of the IEEE, Vol. 93, No. 5, 2005, pp. 9971003.

[8] "System Protection Schemes in Power Networks," CIGRE, Paris, France, TF 38.02.19, 2001.

[9] C. Rehtanz, "Online Stability Assessment and Wide Area Protection Based on Phasor Measurements," Bulk Power System Dynamics and Control V, Onomichi, 2001.

[10] W. H. Quaintance, et al., "Raising Energy Transfer in Corridors Constrained by Voltage Instability-Statnett Case,” IEEE Power Engineering Society Summer Meeting, Vol. 4, 2000, pp. 2021-2026.

[11] M. G. Adamiak, A. P. Apostolov, M. M. Begovic, C. F. Henville, K. E. Martin, G. L. Michel, A. G. Phadke and J. S. Thorp, "Wide Area Protection-Technology and Infrastructures," IEEE Transactions on Power Delivery, Vol.
21, No. 2, 2006, pp. 601-609. doi:10.1109/TPWRD.2005.855481

[12] "N Times 64 Kilobit per Second Optical Fiber Interfaces between Teleprotection and Multiplexer Equipment," IEEE Std. C37.94, 2002.

[13] "Guide for Surge Withstand Capability Tests and Subsequent Revisions,” ANSI/IEEE Std. C37.90a.

[14] E. Veldman, M. Gibescu, J. G. Slootweg and W. L. Kling, "Technical Benefits of Distributed Storage and Load Management in Distributed Grid," IEEE Bucharest of PowerTech, Bucharest, 28 June-1 July 2009, pp. 1-8.

[15] V. Madani and D. Novosel, "Getting a Grip on the Grid," IEEE Spectrum, Vol. 42, No. 12, 2005, pp. 42-47. doi:10.1109/MSPEC.2005.1549781

[16] D. Karlsson, L. Broski and S. Ganesan, "Maximizing Power System Stability through Wide Area Protection," Presented to 57th Annual Conference for Protective Relay Engineers, Texas, 30 March-1 April 2004.

[17] H. Hou, D. You, X. G. Yin, T. Q. Xu, M. L. Jin, X. K. He, B. Wang and Y. B. Xie, "A Newly Developed Line Protection with Ethernet Communication Interface Based on 1EC61850," International Conference on Power System Technology, Chongqing, 22-26 October 2006, pp. 1-4. doi:10.1109/ICPST.2006.321444

[18] S. Shokooh, T. Khandelwal, F. Shokooh, J. Tastet and J. J. Dai, "Intelligent Load Shedding Need for a Fast and Optimal Solution,” IEEE PCIC Europe, 2005.

[19] V. Skendzic and A. Guzmia, "Enhansing Power System Automation through the Use of Real-Time Ethernet," Power Systems Conference: Advanced Metering, Protection, Control, Communication, and Distributed Resources, Clemson, 14-17 March 2006, pp. 480-495. 